\title{
Nitrogen-doped graphene nanosheets as high efficient catalysts for oxygen reduction reaction
}

\author{
CI SuQin ${ }^{1}$, WU YongMin ${ }^{2}$, ZOU JianPing ${ }^{1}$, TANG LongHua ${ }^{2}$, LUO ShengLian ${ }^{1}$, \\ LI JingHong ${ }^{2 *} \&$ WEN ZhenHai ${ }^{1^{*}}$ \\ ${ }^{1}$ Key Laboratory of Jiangxi Province for Ecological Diagnosis-Remediation and Pollution Control, Nanchang Hangkong University, Nanchang \\ 330063, China; \\ ${ }^{2}$ Department of Chemistry, Beijing Key Laboratory for Microanalytical Methods and Instrumentation, Tsinghua University, Beijing 100084, \\ China
}

Received December 22, 2011; accepted March 6, 2012; published online June 26, 2012

\begin{abstract}
It is of great significance in exploring alternative catalysts to platinum (Pt)-based materials for oxygen reduction reaction (ORR), because this reaction is invariably involved in various fuel cells and metal-air batteries. We herein reported the nitrogen doped graphene nanosheets (NGNSs) with pore volume of as high as $3.42 \mathrm{~m}^{3} / \mathrm{g}$ and investigated their potential application as ORR catalysts, it was demonstrated the NGNSs featured high activity, improved kinetics and excellent long-term stability for ORR. The NGNSs were successfully used as cathode catalysts of microbial fuel cells (MFCs) and performed even better than the commercial $\mathrm{Pt} / \mathrm{C}$ (Pt 10\%) catalysts at the maximum power output.
\end{abstract}

nitrogen doped graphene, oxygen reduction reaction, cathode catalysts, microbial fuel cell

Citation: Ci S Q, Wu Y M, Zou J P, et al. Nitrogen-doped graphene nanosheets as high efficient catalysts for oxygen reduction reaction. Chin Sci Bull, 2012, 57: 3065-3070, doi: $10.1007 / \mathrm{s} 11434-012-5253-5$

The coming decades of energy crisis urgently call for the economical, efficient and sustainable energy-conversion technologies to address the challenges of limited fossil resources, environmental issues and the increasing highenergy demands [1]. Fuel cells have been extensively explored and show promises to replace the internal combustion engine due to their advantages including environmentally benign, high efficiency conversion, and high power density [2-5]. One hot topic in research of fuel cell is the oxygen reduction reaction (ORR) occurring in cathodes at low or moderate temperatures that normally need precious platinum (Pt) based materials as catalysts $[6,7]$. Up to now, extensive research interests have been laid on exploring the novel durable, high active, economical, and affordable catalysts to address the existing problems in ORR [8], because ORR has been also of great significance in metal-air batteries and air cathodes for some industrial electrolytic

*Corresponding authors (email: wenzhenhai@yahoo.cn; jhli@tsinghua.edu.cn) processes $[9,10]$. The recent innovation in this subject, by using vertically aligned nitrogen containing carbon nanotubes as the catalysts of ORR, seems to launch on a very promising path to develop cathode catalysts comparable with conventional Pt-based catalysts [11]. Afterwards, various nitrogen doped carbon nanostructures (NCNs), including carbon nanotubes cup, mesoporous graphitic array, and graphene etc., were successfully applied as catalysts of ORR in alkaline medium [12-15]. Despite of these abundant achievements, there are still at least two key issues concerning these NCNs serving as commercial cathode catalysts of fuel cell or metal air. Above all, the sluggish dynamics of the oxygen reduction reaction, which is currently responsible for most of efficiency loss and restricts overall power production in fuel cell or battery systems, did not attain significant improvement on these NCNs catalysts. Next, it still remains a great challenge to develop a facile, reproducible and economical route to produce NCNs in a large scale. For instance, special equipment and ammonia 
gas are necessary via the route of chemical vapor deposition or arc discharge methods, and the assistance of catalysts or template were used for preparing nitrogen containing carbon nanotubes [12], mesoporous carbon [14], and graphene $[16,17]$, which would greatly increase the burdensome of synthesis. We recently developed a general strategy for the fabrication of a new class of nanohybrids consisting of nitrogen doped graphene (NG) functionalized with various metal nitride nanoparticles [18], and this method was extended to a reliable synthetic route to enable facile scalable synthesis of nitrogen doped graphene nanosheets (NGNSs). Surprisingly, the as-developed NGNSs possess an ultrahigh pore volume as high as $3.42 \mathrm{~m}^{3} / \mathrm{g}$ and a considerable surface area, the NGNSs are further investigated to be used as catalysts for ORR, which show excellent electrochemical performance in terms of the current density and long term stability relative to the $\mathrm{Pt} / \mathrm{C}$ catalysts.

\section{Experimental}

\subsection{Materials and characterization}

The NGNSs was prepared through a minor modified route of our recent work [18]. Typically, $2 \mathrm{~mL} \mathrm{50 \%} \mathrm{cyanamide}$ solution (Sigma-Aldrich, USA) was added into $20 \mathrm{~mL}$ graphene oxide solution (about $1.2 \mathrm{mg} / \mathrm{mL}$ ) under stirring with heating at $80^{\circ} \mathrm{C}$ until completely drying, the powders were heated to 750 or $900^{\circ} \mathrm{C}$ under argon protection and annealed for $2 \mathrm{~h}$, the resulted black powder was carefully collected because the products had a low mass density and was very facile to fly out, and denoted as NGNSs-750 and NGNSs900 respectively. For comparison, GO/cyanamide products were treated at $400^{\circ} \mathrm{C}$ for $1 \mathrm{~h}$ to form $\mathrm{C}_{3} \mathrm{~N}_{4}$ polymer on the graphene surface $\left(\mathrm{G}-\mathrm{C}_{3} \mathrm{~N}_{4}\right)$.

The samples were characterized by using a Zeiss EM902 $80 \mathrm{kV}$ Filte transmission electron microscope (TEM), FEI Tecnai F20 ST $200 \mathrm{keV}$ high-resolution transmission electron microscope (HRTEM) and a LEO 1530 field emission scanning electron microscope (FESEM). The X-ray powder diffraction (XRD) patterns were measured in reflection mode on a Bruker D8 diffractometer. X-ray photoelectron spectroscopy (XPS) was conducted using VG ESCA 2000 with an $\mathrm{Mg} \mathrm{K \alpha}$ as source and the $\mathrm{C} 1 \mathrm{~s}$ peak at $284.6 \mathrm{eV}$ as an internal standard.

\subsection{Electrochemical measurement}

All of the electrochemical tests were carried out in a PARSTAT 2273 Potentialstat/Galvanostate electrochemical workstation (Model 273A, Princeton Applied Research). Electrochemical measurements were carried out in a threeelectrode cell using $\mathrm{Ag} / \mathrm{AgCl}$ electrode and $\mathrm{Pt}$ gauze as the reference and the counter electrodes, respectively. The $5 \mathrm{mg}$ catalysts were dispersed ultrasonically in $1 \mathrm{~mL}$ water solution of $0.5 \%$ Nafion to obtain a homogeneous black suspen- sion solution. The $3.0 \mu \mathrm{L}$ aliquot of this solution was pipetted onto glassy carbon electrode surface. The coating was then dried at room temperature in the air. The reproducible $\mathrm{CVs}$ after consecutive scanning were recorded for comparison. The polarization curves for ORR were conducted through the rotating disk electrode (RDE) technique with a scan rate of $5 \mathrm{mV} / \mathrm{s}$. Note that the current has been normalized to surface area of the electrode. The electrolyte was $\mathrm{N}_{2}$ or $\mathrm{O}_{2}$ saturated electrolyte $(0.1 \mathrm{~mol} / \mathrm{L} \mathrm{KOH})$ with or without methanol.

\subsection{Microbial fuel cell test}

The MFC were conducted in a conventional $\mathrm{H}$ configuration consisting of three bottles. Two cathode chambers shared the middle anode chamber that contained a carbon fiber brush electrode with $\mathrm{Ti}$ wire serving as a current collector. Cathode, made of carbon cloth with a projected surface area of $9 \mathrm{~cm}^{2}$ and catalyst, was placed in the cathode chamber and connected to the external circuit by a titanium wire.

The anode chamber was filled with $120 \mathrm{~mL}$ of aqueous medium, containing $0.1 \mathrm{~mol} / \mathrm{L}$ phosphate buffer (PBS, $\mathrm{pH}$ 7.0). Acetate was added in the analyte to reach $0.5 \mathrm{~g} / \mathrm{L}$. The cathodic compartment was filled with an equal volume of $0.1 \mathrm{~mol} / \mathrm{L}$ PBS buffer, continuously saturated with air, and contained an $\mathrm{Ag} / \mathrm{AgCl}$ reference electrode. All reactors operated in duplicate in fed-batch mode conditions at room temperature. Polarization curves were measured using a Gamry Reference 600 potentiostat (Gamry Instruments, USA) at a scan rate of $0.5 \mathrm{mV} / \mathrm{s}$.

\section{Results and discussion}

Figure 1(a) presents the X-ray diffraction (XRD) pattern of the NGNSs, which possesses two characteristic diffraction peaks at $26.1^{\circ}$ and $43.2^{\circ}$ arising from the (002) and (100) plane of graphene sheets respectively. Figure 1(b) presents the high resolution XPS of N1s spectrum of the NGNSs, in which the complex XPS N1s spectra could be fitted to four components of the binding energy, namely pyridine-type nitrogen atoms (398.2 eV), pyrrolic-type $\mathrm{N}$ doping (399.9 $\mathrm{eV})$, graphite-type nitrogen atoms $(401.2 \mathrm{eV})$, and pyridine N-oxide (402.1 eV), indicating that the nitrogen has been doped in NGNSs with multiple status $[19,20]$. XPS measurement further reveals the NGNSs have a $\mathrm{C} / \mathrm{N}$ molar ratio of about 8.2, which is by large identical with the result based on element analysis.

Figure 2 displays a series of typical electron microscopy images from the NGNSs-900. Figure 2(a) and (b) exhibit the field-emission scanning electron microscopy (FESEM) images that describe the general morphology and closeobservation of NGNSs respectively, clearly demonstrating that the NGNSs remained the two dimensional nanosheets structure of graphene. Figure 2(c) presents the typical 

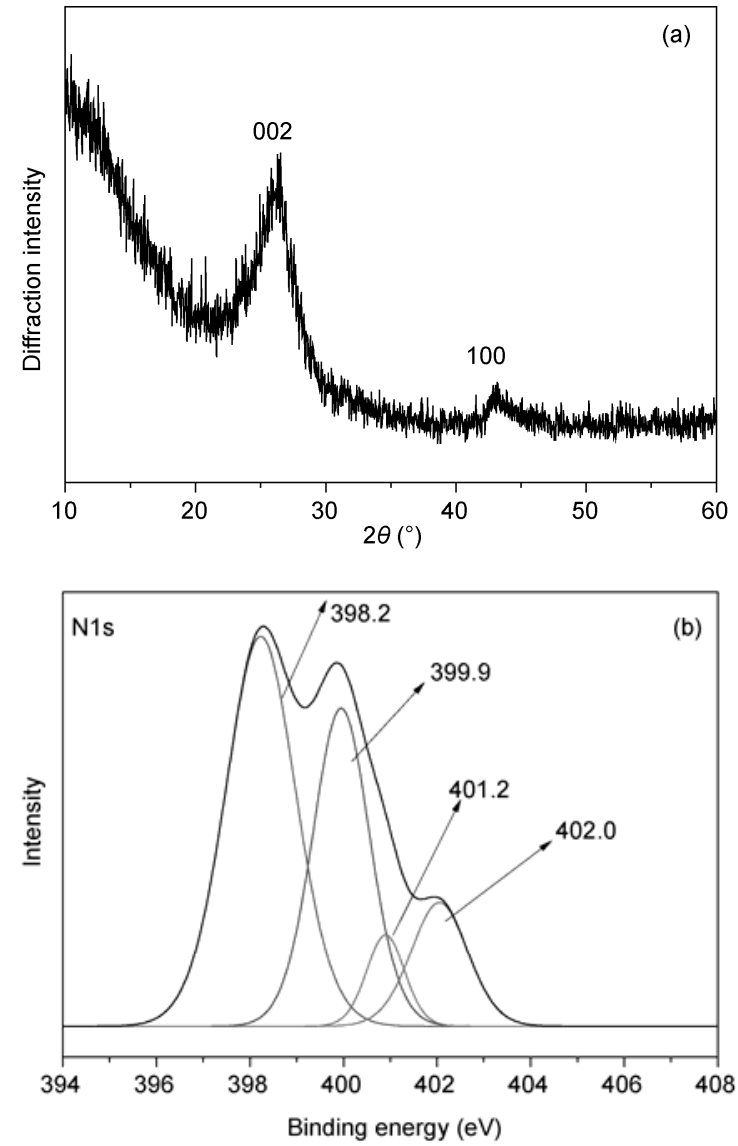

Figure 1 X-ray diffraction pattern of the NGNSs (a) and X-ray photoelectron spectroscopy (XPS) and N1s regions for NGNSs-900 (b). transmission electron microscopy (TEM) image of the NGNSs. One can observe the wrinkle on the graphene surface, which could be aroused by the heat treatment of the pliable GO, which was in consistent with the previous report [21]. The high-resolution TEM (HRTEM) images in Figure 2(d) presents the detailed structure of the NGNSs, a set of wrinkled-lines corresponding to graphite layers can be found on the fringe, indicating the graphitization and stacking of GO induced during heat treatment. The thickness of NGNSs is about 2-4 nm corresponding to a few layers of the graphene based on HRTEM.

We firstly studied the electrochemical catalytic behavior of NGNSs-900 and NGNSs-750 electrodes for ORR via cyclic voltammograms (CVs) technique. For comparison, the thermal reduced graphene (TRGSs) without $\mathrm{N}$ doping, $\mathrm{G} @ \mathrm{C}_{3} \mathrm{~N}_{4}$ and commercial Pt/C modified electrode were also investigated by the same method. Figure 3 shows CVs obtained in the presence of oxygen saturated $0.1 \mathrm{~mol} / \mathrm{L} \mathrm{KOH}$ solution at different electrodes in the range of -0.8 to $0.2 \mathrm{~V}$ at the scan rate of $50 \mathrm{mV} / \mathrm{s}$, from which we can draw the following information. Firstly, the $\mathrm{G} @ \mathrm{C}_{3} \mathrm{~N}_{4}$ displays a negligible current compared with other electrodes since the graphene was completely covered by a poorly-conductive $\mathrm{C}_{3} \mathrm{~N}_{4}$ polymer [22,23], and the slight peak at around $-0.50 \mathrm{~V}$ demonstrated that the $\mathrm{G} @ \mathrm{C}_{3} \mathrm{~N}_{4}$ had a large over-potential and low activity for ORR; secondly, for the TRGSs, there are two poor-defined peaks at around -0.25 and $-0.54 \mathrm{~V}$ respectively, indicating that the TRGSs might catalyze the ORR according to a two-step model [24,25], namely
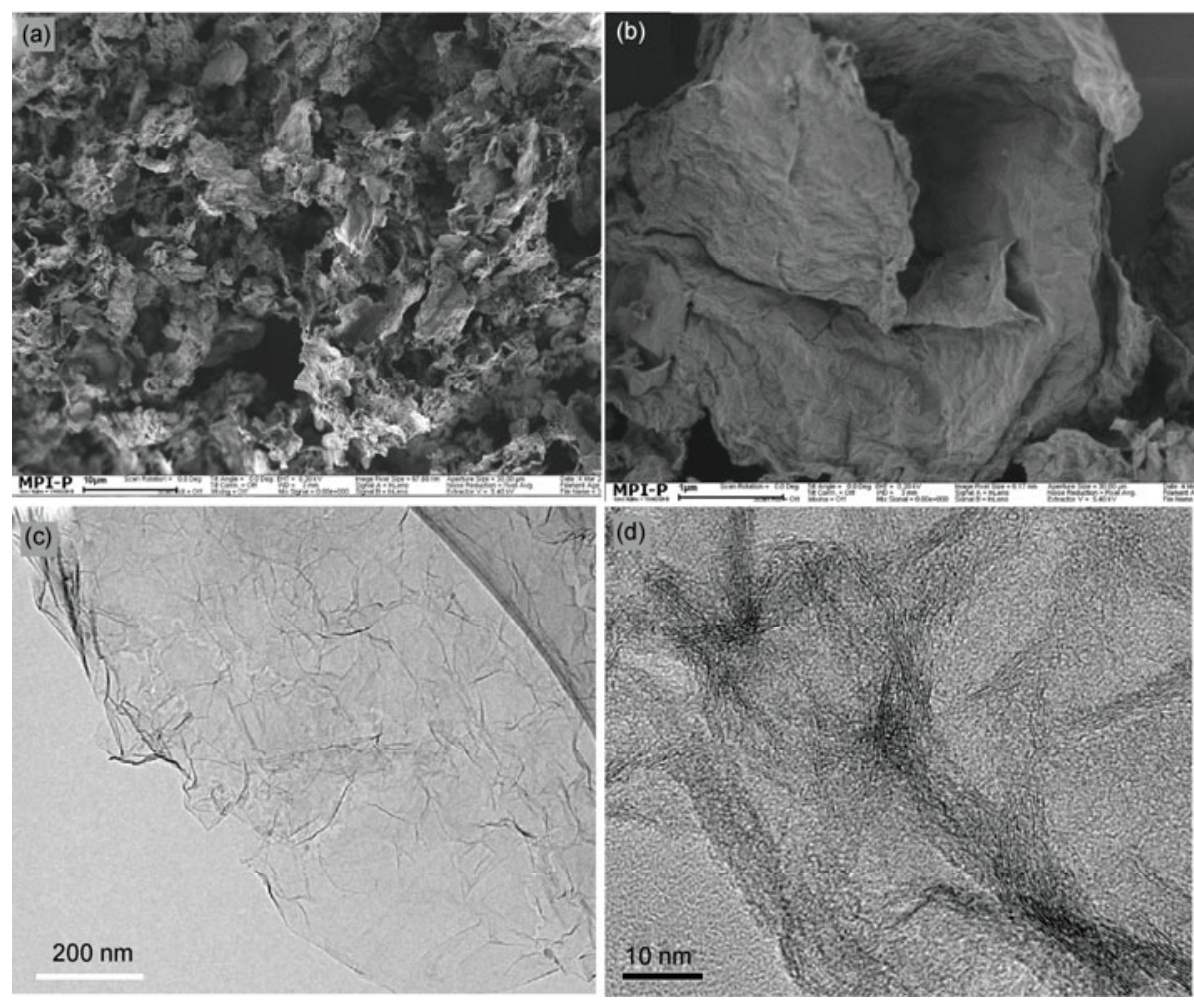

Figure 2 SEM images of NGNSs ((a),(b)), TEM (c) and HRTEM (d) images of NGNSs-900. 


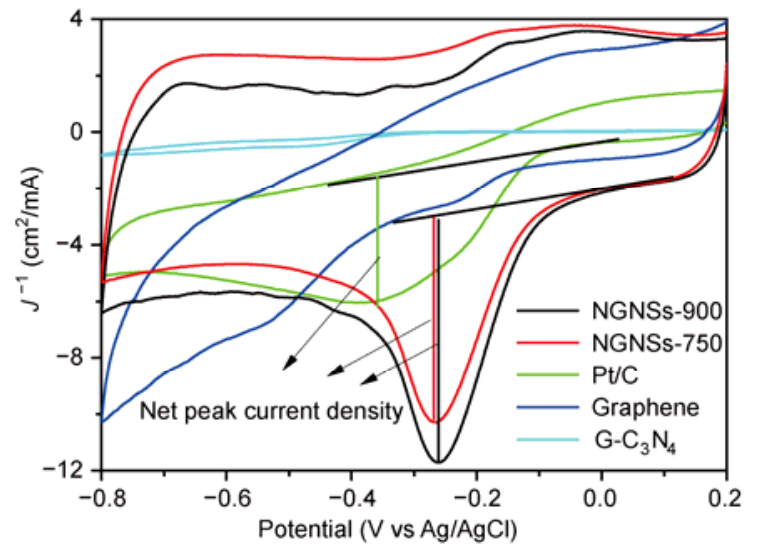

Figure 3 (Color online) Cyclic voltammograms of the different electrodes in oxygen saturated $0.1 \mathrm{~mol} / \mathrm{L} \mathrm{KOH}$ solution in the range of -0.8 to $0.2 \mathrm{~V}$. Scan rate: $50 \mathrm{mV} / \mathrm{s}$.

first reduced oxygen to $\mathrm{H}_{2} \mathrm{O}_{2}$ and then to $\mathrm{H}_{2} \mathrm{O}$. Thirdly, the NGNSs-900 electrode manifests the best catalytic performance for ORR among these electrodes in several electrochemical parameters, including the current density and peak potential of ORR. For instance, quite different from $\mathrm{G} @ \mathrm{C}_{3} \mathrm{~N}_{4}$, the samples after further heat-treatment (NGNSs750 and NGNSs-900) shows a significantly improved background current at potential range from 0 to $0.2 \mathrm{~V}$, indicating the semiconductor-like $\mathrm{C}_{3} \mathrm{~N}_{4}$ covered on graphene have been decomposed with annealing above 750. Additionally, one distinct reduction peak, arising from oxygen reduction, appears at the potential of about $-0.25 \mathrm{~V}$. The net peak current density, namely the value of peak current subtracting the background current, approached 6.92 and $8.75 \mathrm{~mA} / \mathrm{cm}^{2}$ for the NGNSs-750 and NGNSs-900 respectively. Both values were much higher than that of commercial Pt/C catalysts $\left(5.12 \mathrm{~mA} / \mathrm{cm}^{2}\right)$. Finally, the NGNSs-900 and $\mathrm{Pt} / \mathrm{C}$ electrode show the onset potential at around 0.013 and $-0.06 \mathrm{~V}$, respectively, suggesting that the NGNSs-900 can somehow reduce the over-potential. The rotating disk electrode (RDE) voltammograms was also performed on these electrodes for ORR (not shown), as expected, the NGNSs900 shows the highest limited current density among these electrodes, confirming the above CVs results. According to the cyclic voltammograms, the NGNSs-900 obviously perform the best catalytic activity for ORR among the above catalysts, therefore, the NGNSs-900 was afterward selected to be investigated through the further electrochemical experiments.

Up to now, the long-term stability remains a major concern in Pt-based cathode catalysts of fuel cell system. Therefore, the durability experiments were further conducted in $\mathrm{O}_{2}$ saturated $0.1 \mathrm{~mol} / \mathrm{L} \mathrm{KOH}$ solution after 1000 cyclic potential sweeping between 0.4 and $-1.0 \mathrm{~V}$ at the $\mathrm{Pt} / \mathrm{C}$ and NGNSs-900 electrodes respectively. Figure 4(a) and (b) show the RDE voltammogram curves recorded in the new-made electrode and with $1000 \mathrm{CVs}$ cycles at the $\mathrm{Pt} / \mathrm{C}$ and NGNSs-900 electrodes respectively. The $\mathrm{Pt} / \mathrm{C}$ shows a drastic decrease on limited current density accompanied with an obvious negative shift of onset potential with cycling, which could be attributed to the poison effect and loss of electrochemical surface area [26]. In stark contrast, the NGNSs-900 electrode displays a very slight change of voltammogram curve within 1000 cycles, highlighting that the NGNSs-900 did possess a superior long-term stability to the $\mathrm{Pt} / \mathrm{C}$ catalysts.

To better understand the catalytic properties of NGNSs900 , the RDE voltammograms (Figure 4(c)) were conducted through scanning the potential from 0.1 to $-0.8 \mathrm{~V}$ at the scan rate of $5 \mathrm{mV} / \mathrm{s}$ with different rotation rates. Figure 4(d) profiles the corresponding Koutecky-Levich plots that reveal the inverse current density $\left(J^{-1}\right)$ as a function of the inverse of the square root of the rotation rate $\left(\omega^{-1 / 2}\right)$ at different potential. These Koutecky-Levich plots possessed good linearity and parallelism, indicating consistent electron transfer and the first-order kinetics with respect to ORR [27].

Based on the Koutecky-Levich equation:

$$
1 / J_{\text {lim }}=1 / J_{\text {Lev }}+1 / J_{\mathrm{k}} \text {. }
$$

The Koutecky-Levich plot was obtained to present the relationship of $j_{\text {lim }}{ }^{-1}$ versus $\omega^{-1 / 2}$, where $J_{\text {Lev }}=0.62 n F C D^{2 / 3} v^{-1 / 6} \omega^{1 / 2}$ ( $n$, number of electrons; $F$ (Faraday) $=96486.4$ Coulombs, $C$ (molar concentration of oxygen $)=1.2 \times 10^{-3} \mathrm{~mol} / \mathrm{L}$ at room temperature, $D$ (diffusion coefficient of oxygen in water) $=1.9 \times 10^{-5} \mathrm{~cm} / \mathrm{s}, v$ (kinematic viscosity of the solution at room temperature) $=0.01 \mathrm{~cm}^{2} / \mathrm{s}$, and $\omega$ (angular velocity of the disk) $=2 \pi N$, where $N$ is the linear rotation speed); and $J_{\mathrm{k}}$ is the kinetic current density, which determines the rate of kinetically limited reaction of ORR. Basing on the slope and interception, the electron number occurred in ORR and kinetic current density can be calculated. The electron transfer number for ORR was calculated to be about 4.04 at $-0.25 \mathrm{~V}$, indicating that the ORR for NGNSs-900 electrode predominantly proceeded through the four electron transfer reaction pathway that produced water. In addition, the kinetic current density at $-0.25 \mathrm{~V}$ was calculated to be $23.2 \mathrm{~mA} / \mathrm{cm}^{2}$ based on the intercept of the Koutecky-Levich plots, which was wo times higher than that of the $\mathrm{Pt} / \mathrm{C}$ catalysts $(8.4 \mathrm{~mA} /$ $\mathrm{cm}^{2}$ ). It should be noted that the kinetic current density with NGNSs-900 also shows much higher than that of the previously reported mesoporous carbon, graphene and carbon nanotubes $[12,13]$.

The above results clearly reveal that NGNSs-900 exhibit improved catalytic performance for ORR in comparison with the $\mathrm{Pt} / \mathrm{C}$ composites catalysts. The following factors can be summarized to elucidate the fundamental aspects of high activity and excellent stability of NGNSs-900 catalyst for ORR. First of all, the NGNSs-900 completely maintains the 2D nanostructure of graphene with high conductivity, large surface area and ultrahigh pore volume. These features are of significance for providing plentiful active sites for ORR and accelerating electron transfer rate or decreasing electric resistance. Additionally, as the NGNSs-900 can 

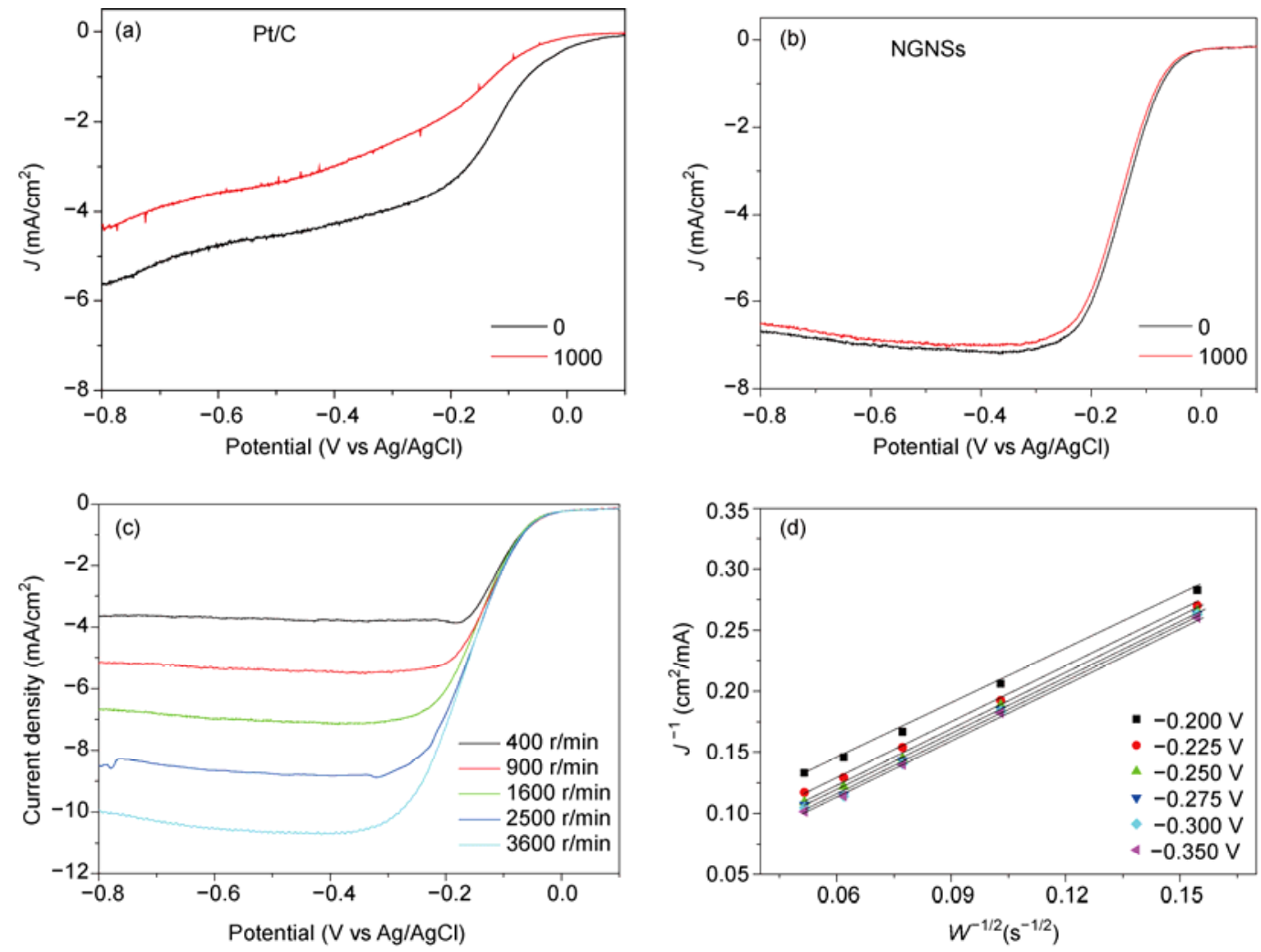

Figure 4 (Color online) The linear-sweep voltammograms recorded after 0 and $1000 \mathrm{CVs}$ cycles in oxygen-saturated $0.1 \mathrm{~mol} / \mathrm{L} \mathrm{KOH}$ with $1600 \mathrm{r} / \mathrm{min}$ and a scan rate of $5 \mathrm{mV} / \mathrm{s}$ on the Pt/C electrode (a) and NGNSs-900 electrode (b) (CVs range: -1.0 to $0.4 \mathrm{~V}$, scan rate: $0.1 \mathrm{~V} / \mathrm{s}$ ). (c) The linear-sweep voltammograms recorded with different rotation rates in an $\mathrm{O}_{2}$ saturated $0.1 \mathrm{~mol} / \mathrm{L} \mathrm{KOH}$ solution on NGNSs-900 electrode at a scan rate of $5 \mathrm{mV} / \mathrm{s}$. (d) Koutecky-Levich plot of current density versus $w^{-1 / 2}$ at different potentials on NGNSs-900 electrode.

independently act as the ORR catalysts without loading other catalytic nanoparticles (e.g. Pt), this could avoid the activity loss resulting from the catalytic nanoparticles peeling off from the supporting materials. Furthermore, the NGNSs-900 can efficiently catalyze $\mathrm{O}_{2}$ electrochemical reduction in the 4-electron transfer pathway to produce $\mathrm{H}_{2} \mathrm{O}$ rather than the 2-electron pathway to $\mathrm{H}_{2} \mathrm{O}_{2}$.

It should be noted that the NGNSs-900 also exhibits at least two appealing features compared to the $\mathrm{N}$-doped carbon nanostructures reported previously. On the one hand, despite of a common surface area of $465.2 \mathrm{~m}^{2} / \mathrm{g}$, the NGNSs-900 has a porous volume as high as $3.42 \mathrm{~m}^{3} / \mathrm{g}$, while most nanostructured carbon normally had a pore volume less than $2.5 \mathrm{~m}^{3} / \mathrm{g}$. It is generally viewed that larger surface area indicates more catalyzing activate sites on the surface, while the higher pore volume signifies more accommodating capability of $\mathrm{O}_{2}$ and promotes the mass transfer in interface, it is therefore reasonable to propose that the ultrahigh pore volume in the NGNSs-900 could give rise to the significant improvement of kinetic current density. On the other hand, the NGNSs-900 also has a higher $\mathrm{N}$ content, as the doped- $\mathrm{N}$ acts a quite important role in catalyzing ORR, high doped-N in the NGNSs-900 is possibly another advantage that could provide more catalytic centers for ORR.

We further set up an H-type MFC to make comparable study between the NGNSs-900 and Pt/C as an alternative cathode catalyst. Both NGNSs-900 and PT/C electrodes were plugged in a different chamber so that they could share the same anode chamber to fairly evaluate the performance of the two electrodes for MFCs [14]. Polarization tests were examined to investigate the performance of both MFCs. As shown in Figure 5, one can observe a slight difference in open circuit voltage $\left(V_{\text {oc }}\right)$ between the NGNSs-900-MFC

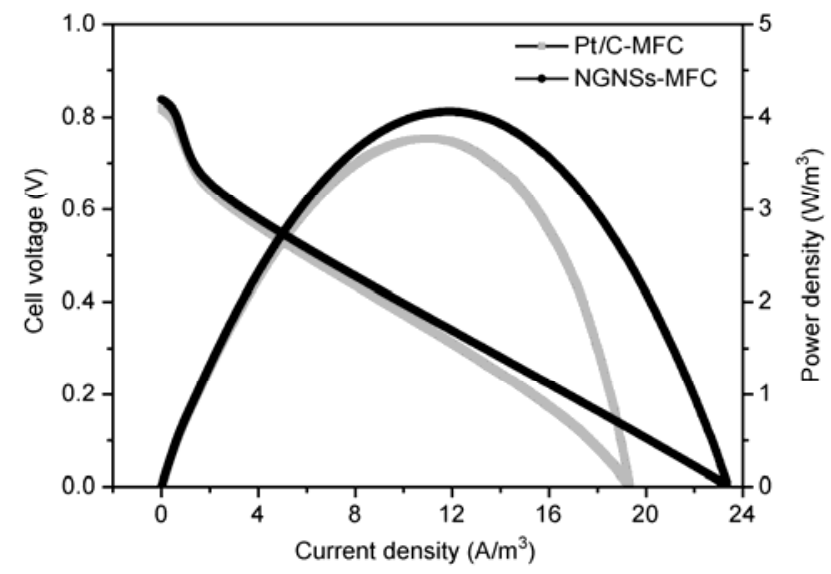

Figure 5 MFC polarization and power density curves with $\mathrm{Pt} / \mathrm{C}$ and NGNSs-900 cathode. Note: the power density was normalized based on the volume of anode solution. 
and the Pt/C-MFC, which was 0.84 and $0.82 \mathrm{~V}$, respectively. It should be noted that both the current density and power density were normalized to the volume of the anode solution. It was found that the maximal current density was $23.34 \mathrm{~A} / \mathrm{m}^{3}$ in the NGNSs-900-MFC, which is around 1.2 times higher than that achieved in $\mathrm{Pt} / \mathrm{C}-\mathrm{MFC}$ under identical conditions $\left(19.35 \mathrm{~A} / \mathrm{m}^{3}\right)$. Meanwhile, the NGNSs-900-MFC achieved a maximum power density $\left(P_{\max }\right)$ of $4.06 \mathrm{~W} / \mathrm{m}^{3}$ at the current density of $11.88 \mathrm{~A} / \mathrm{m}^{3}$, while the maximum power density of the $\mathrm{Pt} / \mathrm{C}-\mathrm{MFC}$ was $3.77 \mathrm{~W} / \mathrm{m}^{3}$ at the current density of $11.33 \mathrm{~A} / \mathrm{m}^{3}$. These MFC testing results revealed that the NGNSs-900 did show great potential for practical application.

\section{Conclusion}

In summary, we have developed a facile, convenient, economical and effective method to prepare the nitrogen doped graphene nanosheets with ultrahigh pore volume. As a potential application, the NGNSs-900 displays much better electrochemical catalytic performance for oxygen reduction reaction than the commercial $\mathrm{Pt} / \mathrm{C}$ catalysts in regard to catalytic activity and long-term stability. The NGNSs-900 was successfully used as the alternative catalysts to Pt based cathode catalysts in MFC systems. To benefit from the facile synthesis of the NGNSs-900 in this route and the advantages of electrochemical performance, the present work may provide a promising route to replace the expensive cathode catalysts involved in fuel cell or battery systems.

This work was supported by the National Basic Research Program of China (2011CB935704), the National Natural Science Foundation of China (20903055), Key Program Foundation of Jiangxi Educational Committee (GJJ09019, GJJ09491) and Natural Science Foundation of Jiangxi Province (2009GZH0085).

1 Qiao Y, Bao S J, Li C M. Electrocatalysis in microbial fuel cellsfrom electrode material to direct electrochemistry. Energ Environ Sci, 2010, 3: 544-553

2 Borup R, Meyers J, Pivovar B, et al. Scientific aspects of polymer electrolyte fuel cell durability and degradation. Chem Rev, 2007, 107: 3904-3951

3 He P, Liu H, Li Z, et al. Electrodeposition of platinum in room temperature ionic liquids and its electrocatalytic effect on electrooxidation of methanol. J Electrochem Soc, 2005, 152: E146-E153

$4 \mathrm{Li} \mathrm{Y} \mathrm{M}$, Tang L H, Li J H. Pt/graphene nano composites as the anode catalyst of methanol oxidation. Electrochem Commun, 2009, 11: 846-849

5 Wen $\mathrm{Z} \mathrm{H}$, Wang Q, Li J H. Template synthesis of aligned carbon nanotubes arrays using glucose as carbon source: Pt decorating its inner and outer surfaces for fuel cell catalysts. Adv Funct Mater, 2008, 18: 959-964

6 Christensen P A, Hamnett A, Linares-Moya D. Oxygen reduction and fuel oxidation in alkaline solution. Phys Chem Chem Phys, 2011, 13: $5206-5214$
7 Wen $\mathrm{Z} \mathrm{H}$, Li J H. Hierarchically structured carbon nanocomposites as electrode materials for electrochemical energy storage, conversion and biosensor systems. J Mater Chem, 2009, 19: 8707-8713

8 Lefevre M, Proietti E, Jaouen F, et al. Iron-based catalysts with improved oxygen reduction activity in polymer electrolyte fuel cells. Science, 2009, 324: 71-74

9 Cheng F Y, Shen J A, Peng B, et al. Rapid room-temperature synthesis of nanocrystalline spinels as oxygen reduction and evolution electrocatalysts. Nat Chem, 2011, 3: 79-84

10 Strasser P, Koh S, Anniyev T, et al. Lattice-strain control of the activity in dealloyed core-shell fuel cell catalysts. Nat Chem, 2010, 2: 454-460

11 Gong K P, Du F, Xia Z H, et al. Nitrogen-doped carbon nanotube arrays with high electrocatalytic activity for oxygen reduction. Science, 2009, 323: 760-764

12 Geng D S, Chen Y, Chen Y G, et al. High oxygen-reduction activity and durability of nitrogen-doped graphene. Energ Environ Sci, 2011, 4: 760-764

13 Yang W, Fellinger T P, Antonietti M. Efficient metal-free oxygen reduction in alkaline medium on high-surface-area mesoporous nitrogen-doped carbons made from ionic liquids and nucleobases. $\mathbf{J}$ Am Chem Soc, 2011, 133: 206-209

14 Wen Z H, Ci S Q, Zhang F, et al. Nitrogen-enriched core-shell structured $\mathrm{Fe} / \mathrm{Fe}_{3} \mathrm{C}-\mathrm{C}$ nanorods as advanced electrocatalysts for oxygen reduction reaction. Adv Mater, 2012, 24: 1399-1404

15 Ma Y, Zhang L, Li J J, et al. Carbon-nitrogen/graphene composite as metal-free electrocatalyst for the oxygen reduction reaction. Chin Sci Bull, 2011, 56: 3583-3589

16 Wang Y, Shao Y, Matson D W, et al. Nitrogen-doped graphene and its application in electrochemical biosensing. ACS Nano, 2010, 4: 1790-1798

17 Chen D, Tang L H, Li J H. Graphene-based materials in electrochemistry. Chem Soc Rev, 2010, 39: 3157-3180

18 Wen $\mathrm{Z} \mathrm{H}$, Cui S M, Pu H H, et al. Metal nitride/graphene nanohybrids: Neneral synthesis and multifunctional titanium nitride/ graphene electrocatalyst. Adv Mater, 2011, 23: 5445-5450

19 Wei D, Liu Y, Wang Y, et al. Synthesis of N-doped graphene by chemical vapor deposition and its electrical properties. Nano Lett, 2009, 9: 1752-1758

20 van Dommele S, Romero-Izquirdo A, Brydson R, et al. Tuning nitrogen functionalities in catalytically grown nitrogen-containing carbon nanotubes. Carbon, 2008, 46: 138-148

21 Jafri R I, Rajalakshmi N, Ramaprabhu S. Nitrogen doped graphene nanoplatelets as catalyst support for oxygen reduction reaction in proton exchange membrane fuel cell. J Mater Chem, 2010, 20: 7114-7117

22 Wang X C, Maeda K, Thomas A, et al. A metal-free polymeric photocatalyst for hydrogen production from water under visible light. Nat Mater, 2009, 8: 76-80

23 Wang X C, Maeda K, Chen X F, et al. Polymer semiconductors for artificial photosynthesis: Hydrogen evolution by mesoporous graphitic carbon nitride with visible light. J Am Chem Soc, 2009, 131: 1680-1681

24 Zhou Q, Li C M, Li J, et al. Electrocatalysis of templateelectrosynthesized cobalt-porphyrin/polyaniline nanocomposite for oxygen reduction. J Phys Chem C, 2008, 112: 18578-18583

25 Wen Z H, Liu J, Li J H. Core-shell Pt-C nanoparticles embedding in mesoporous carbon as methanol tolerant cathode catalyst in direct methanol fuel cell. Adv Mater, 2008, 20: 743-747

26 Chen Z W, Waje M, Li W Z, et al. Supportless Pt and PtPd nanotubes as electrocatalysts for oxygen-reduction reactions. Angew Chem Int Ed, 2007, 46: 4060-4063

27 Collman J P, Denisevich P, Konai Y, et al. Electrode catalysis of the four-electron reduction of oxygen to water by dicobalt face-to-face porphyrins. J Am Chem Soc, 1980, 102: 6027-6036

Open Access This article is distributed under the terms of the Creative Commons Attribution License which permits any use, distribution, and reproduction in any medium, provided the original author(s) and source are credited. 